\title{
NASA Glenn's Contributions to Aircraft Engine Noise Research
}

\author{
Dennis L. Huff \\ NASA Glenn Research Center \\ AIAA Joint Propulsion Conference \\ July 29, 2014
}

http://ntrs.nasa.gov/
NASA/TP-2013-217818 


\section{Long History of Engine Noise Research}

- NASA Lewis initially focused on engine performance.

- First engine noise research started in the 1950's for turbojets.

- Space program consumed workforce in 1960's.

- Aeronautics research resumed in 1966 to focus on rapid air traffic growth issues (airport congestion, noise and pollution).

- There has been continuous work on engine noise ever since:

- Quieter engines for STOL aircraft

- High-speed propellers

- Jet noise

- Higher bypass ratio engines \& combustion noise

- Open rotors developed through NASA research programs. 


\section{Engine Noise Sources}

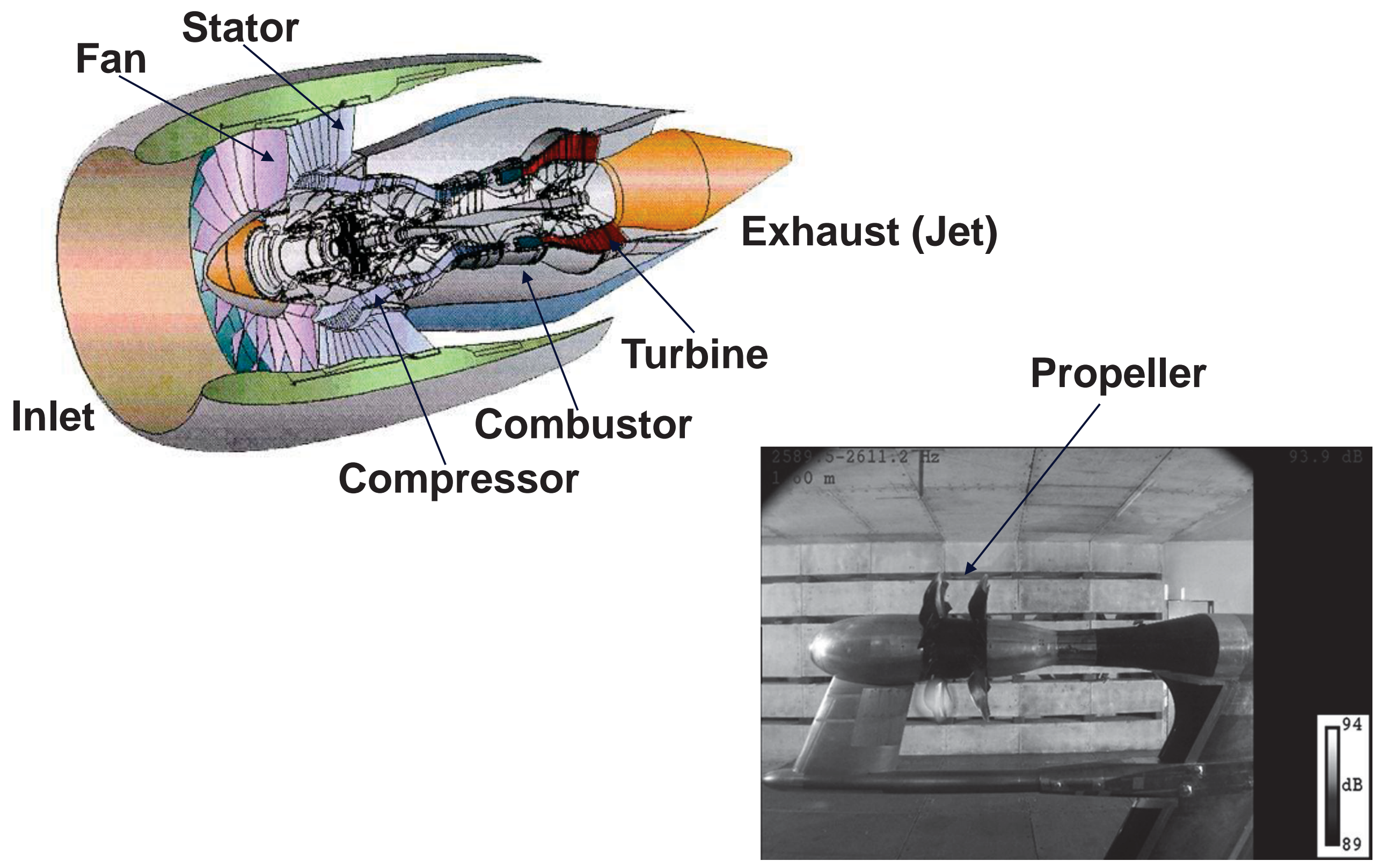




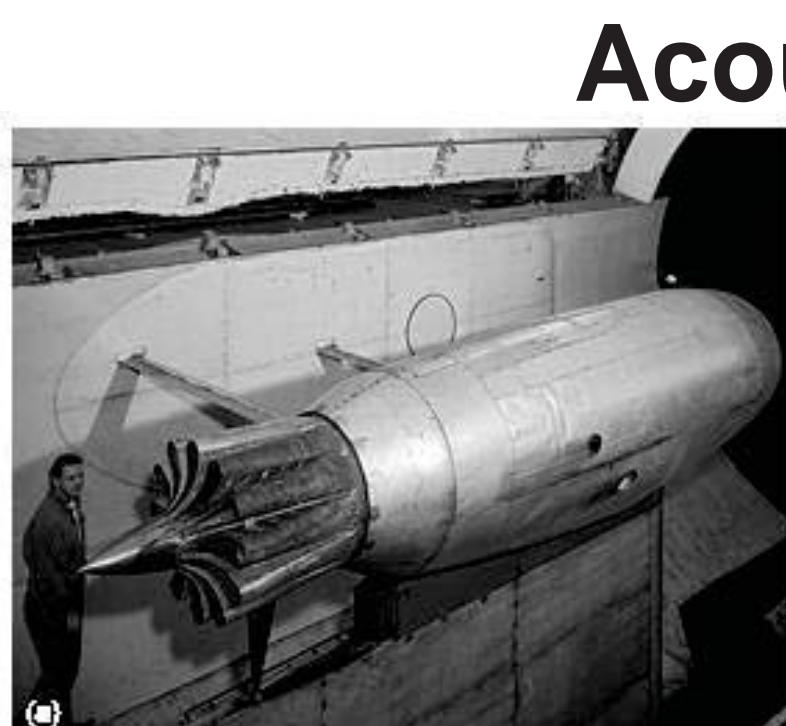

\section{Acoustic Test Facilities - 1950s}
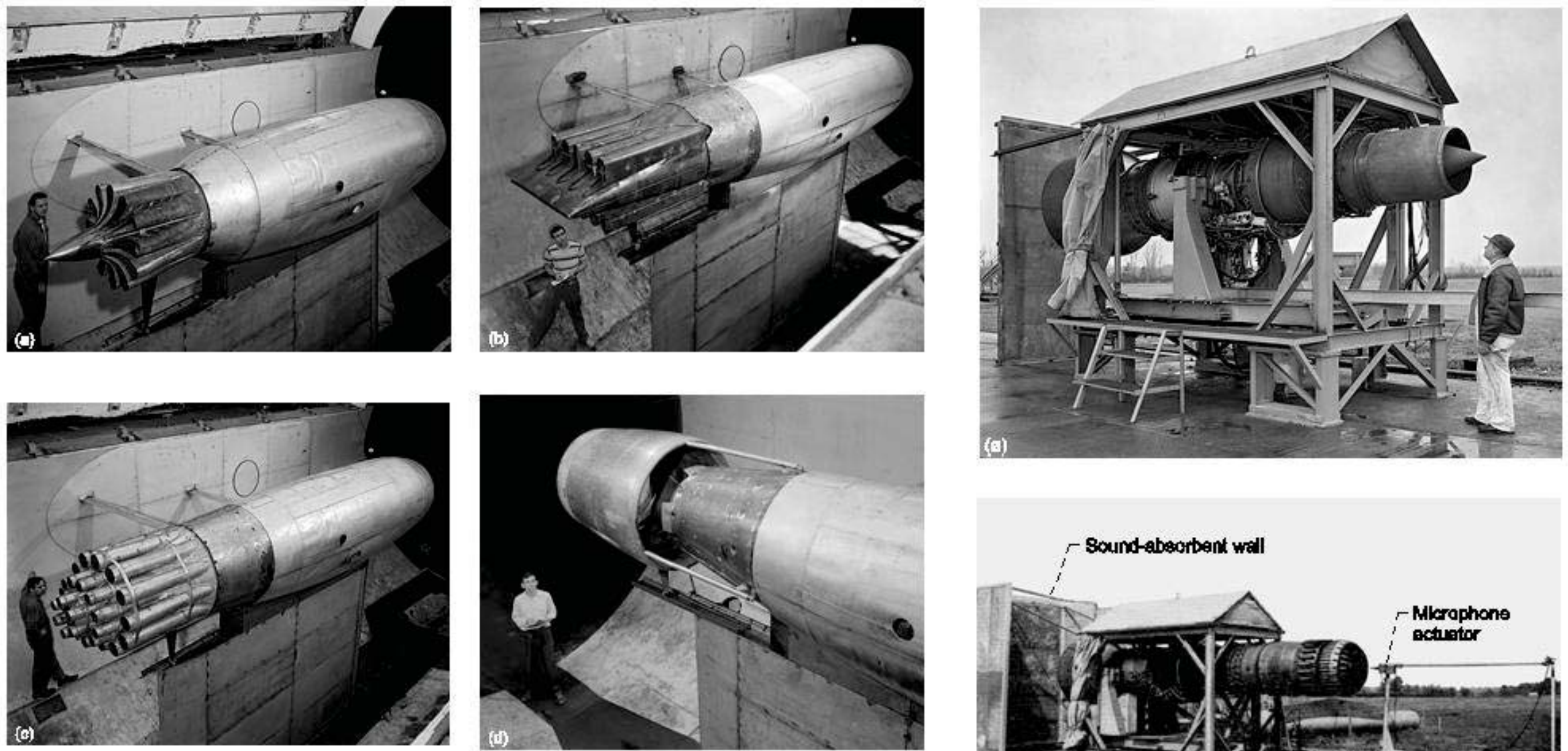

\section{Altitude Wind Tunnel}

Initial tests used full scale engines and focused on jet noise. NACA turbojet research concluded a 12-lobe nozzle had the least thrust loss $(3.2 \%$ at $M=0.50)$ and could provide up to 5 to $6 \mathrm{~dB}$ reduction for peak takeoff noise. 


\section{Acoustic Test Facilities - 1970s}

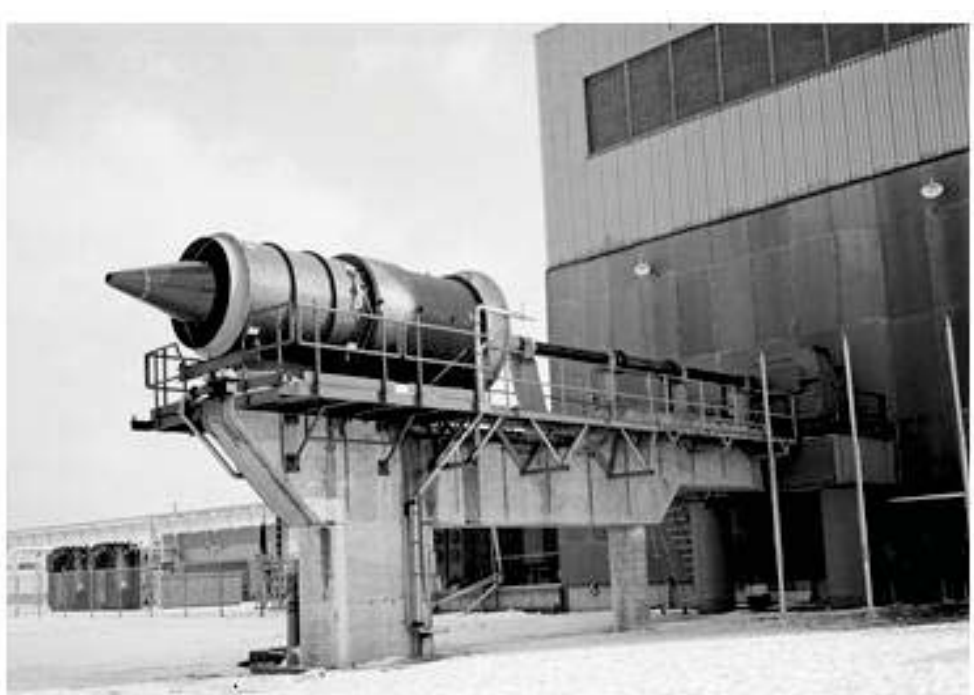

(a)

\section{Quiet Engine Program Fan Rig}

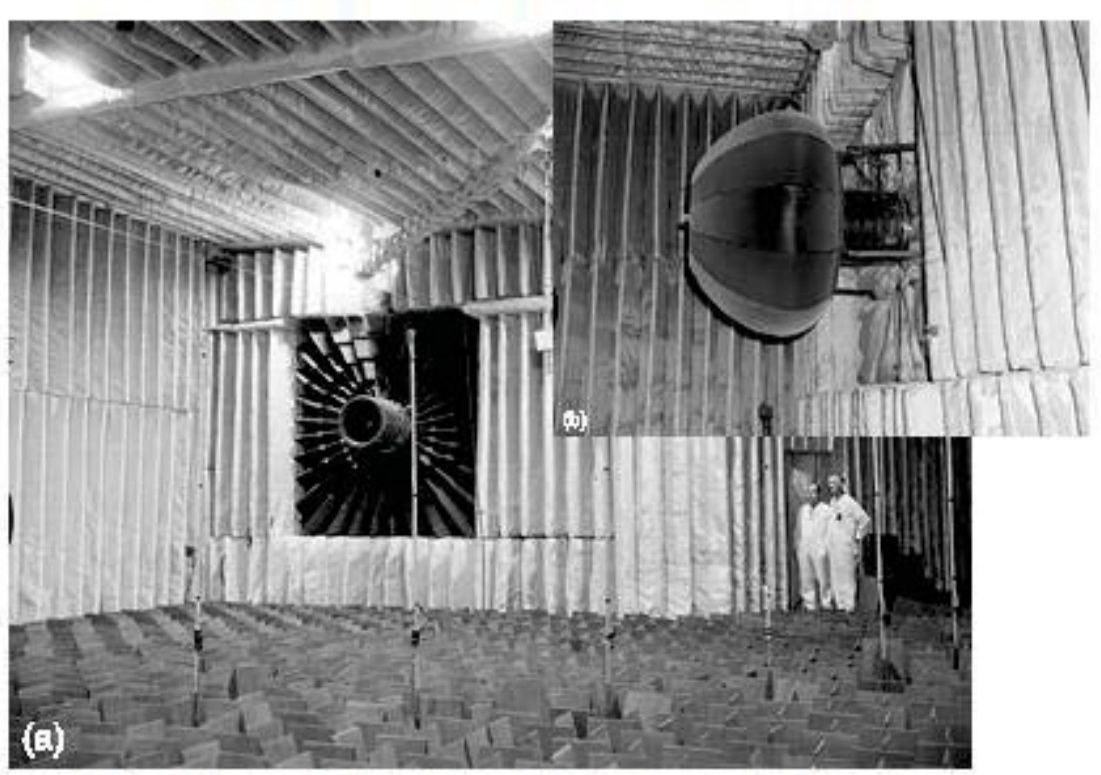

Anechoic Chamber for Fan Noise

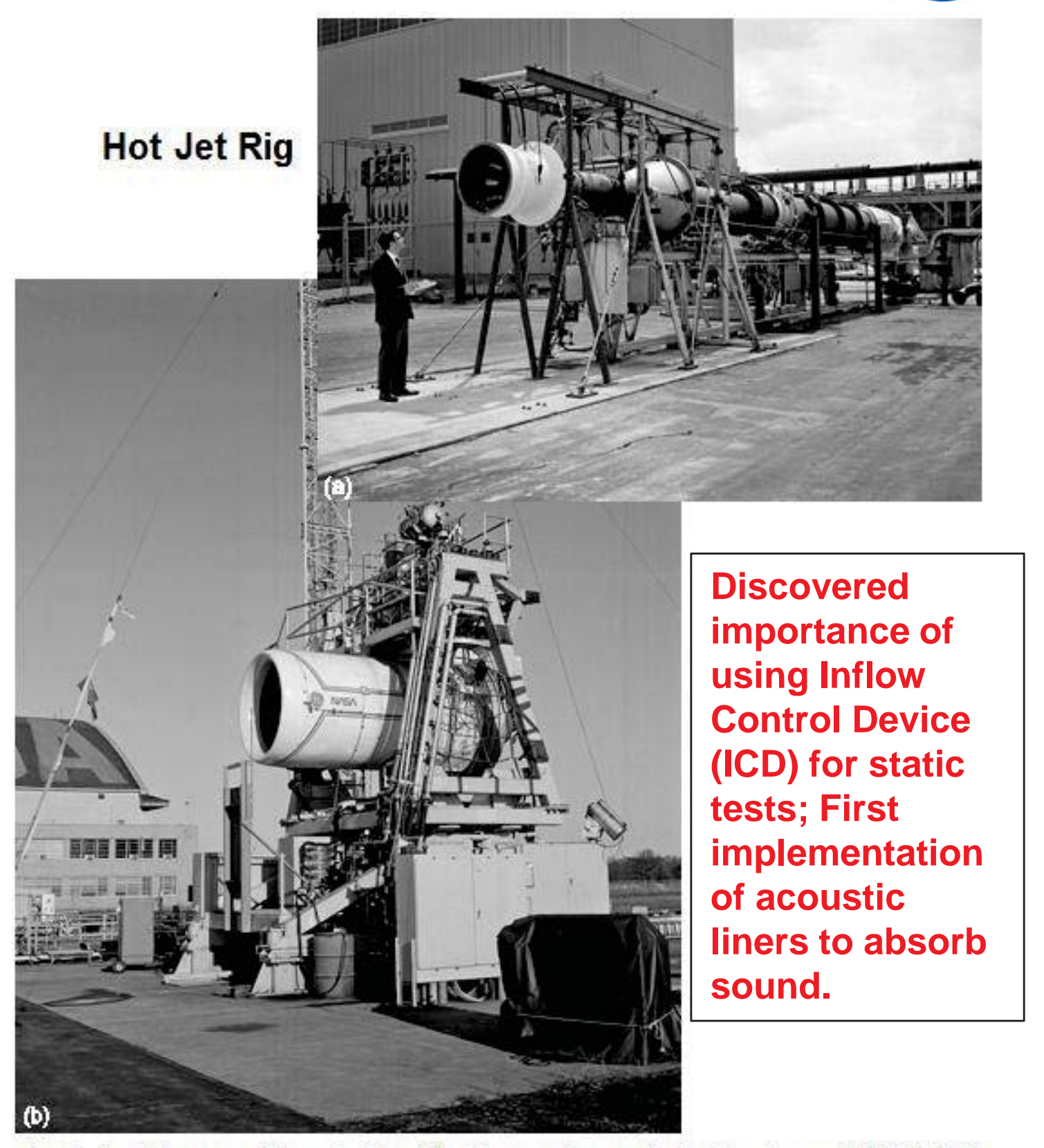

Quiet, Clean, Short-Haul, Experimental Engine (QCSEE) 


\section{Acoustic Test Facilities - Current}

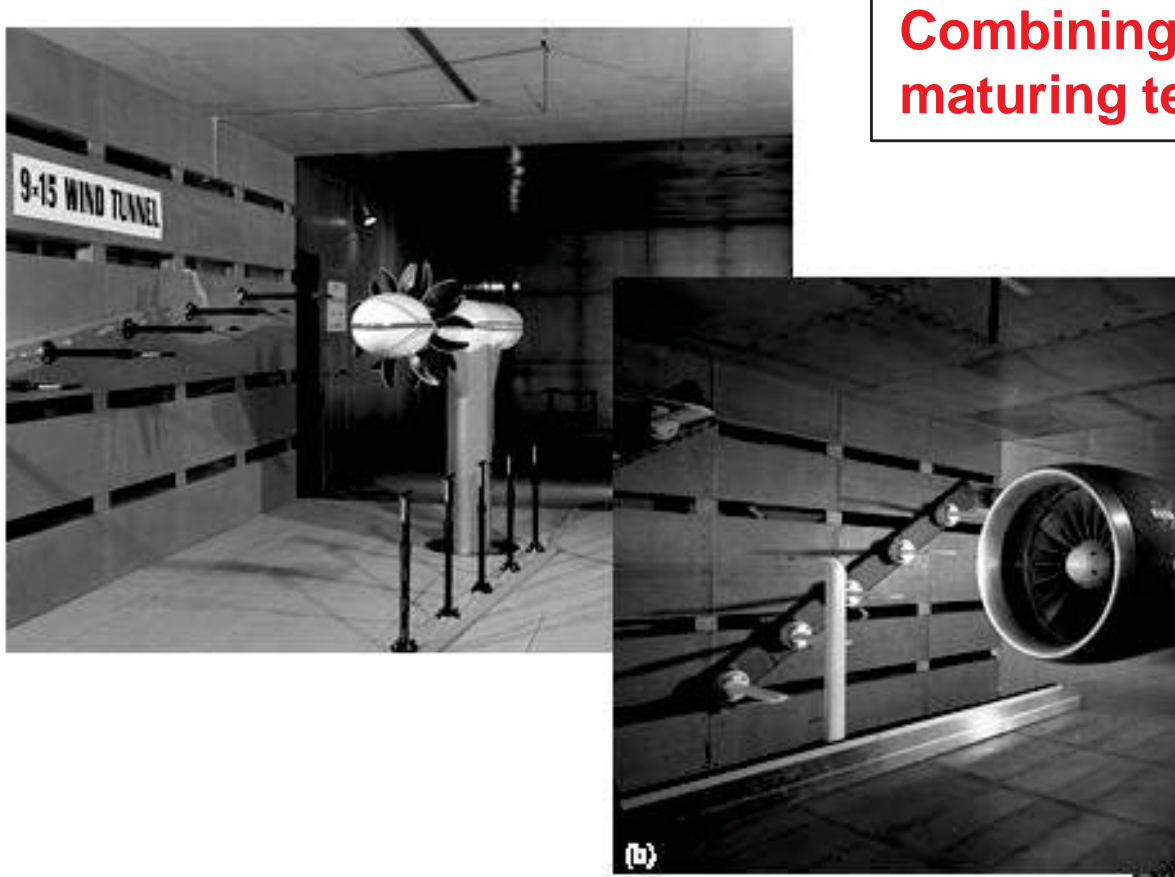

Combining aerodynamic and acoustic research important for maturing technologies to level needed for engine applications.

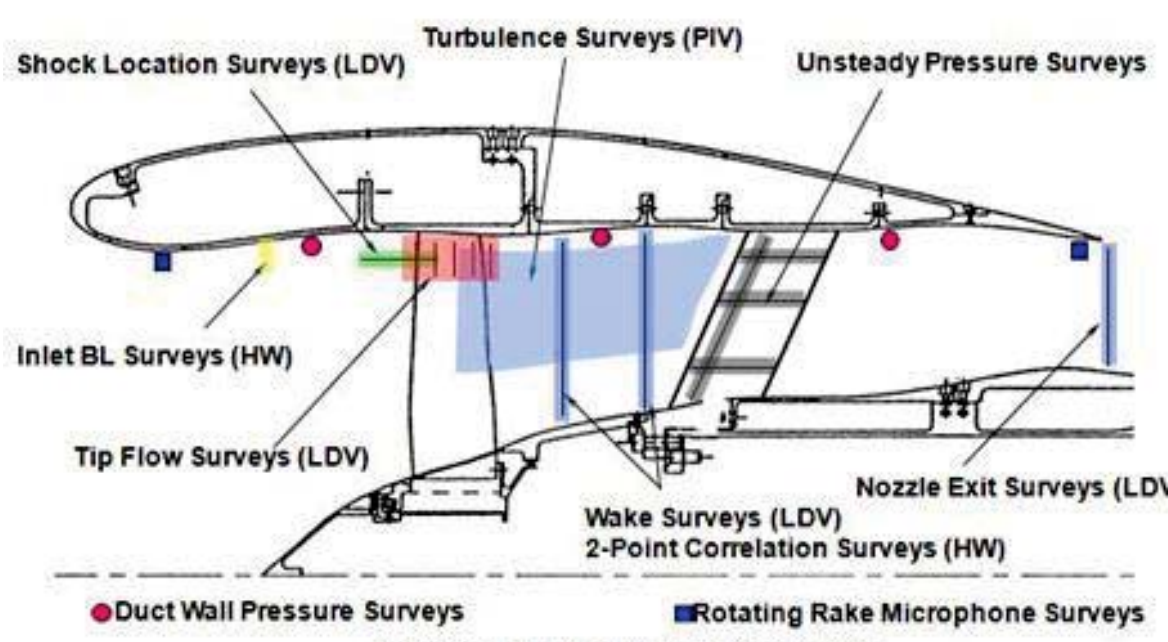

Traversing Microphone Farfield Surveys

9' x 15' Low-Speed Wind Tunnel

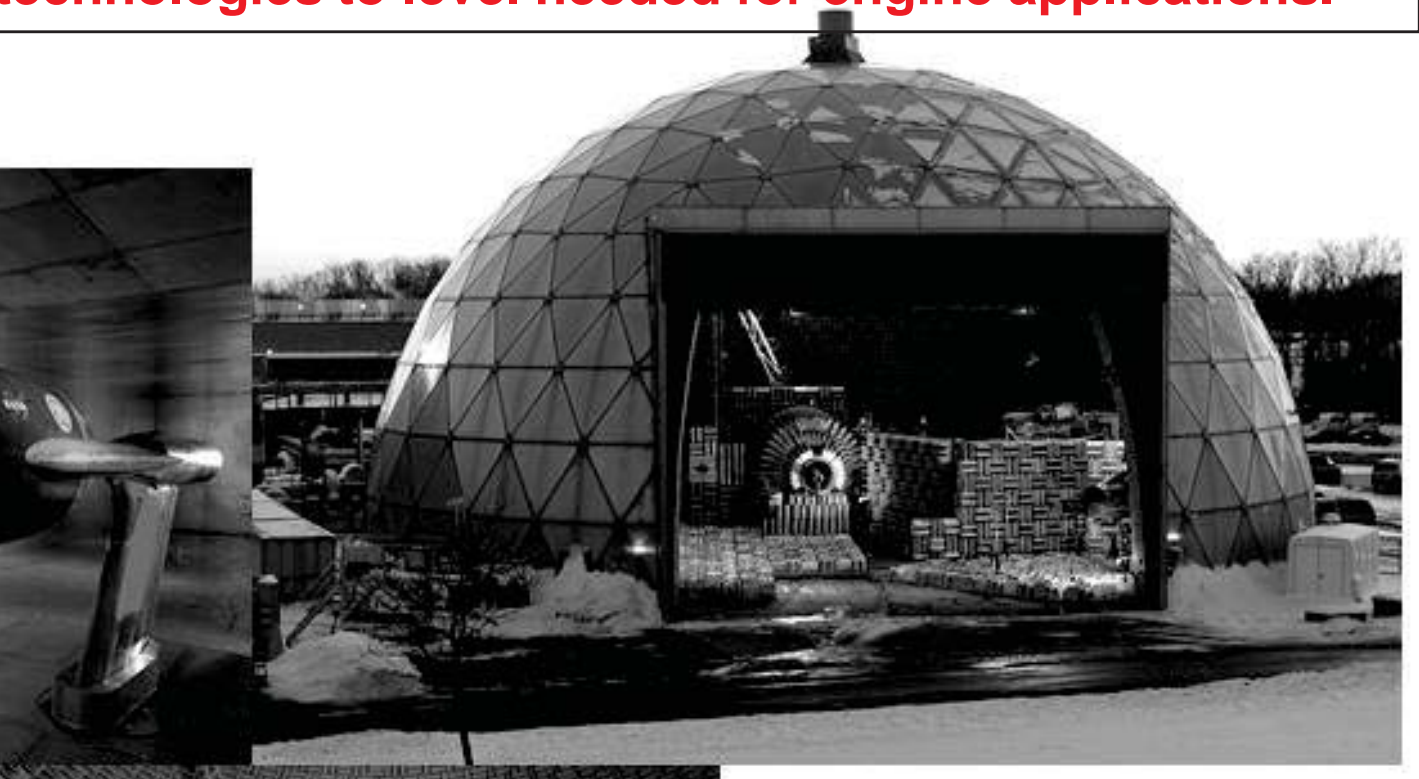

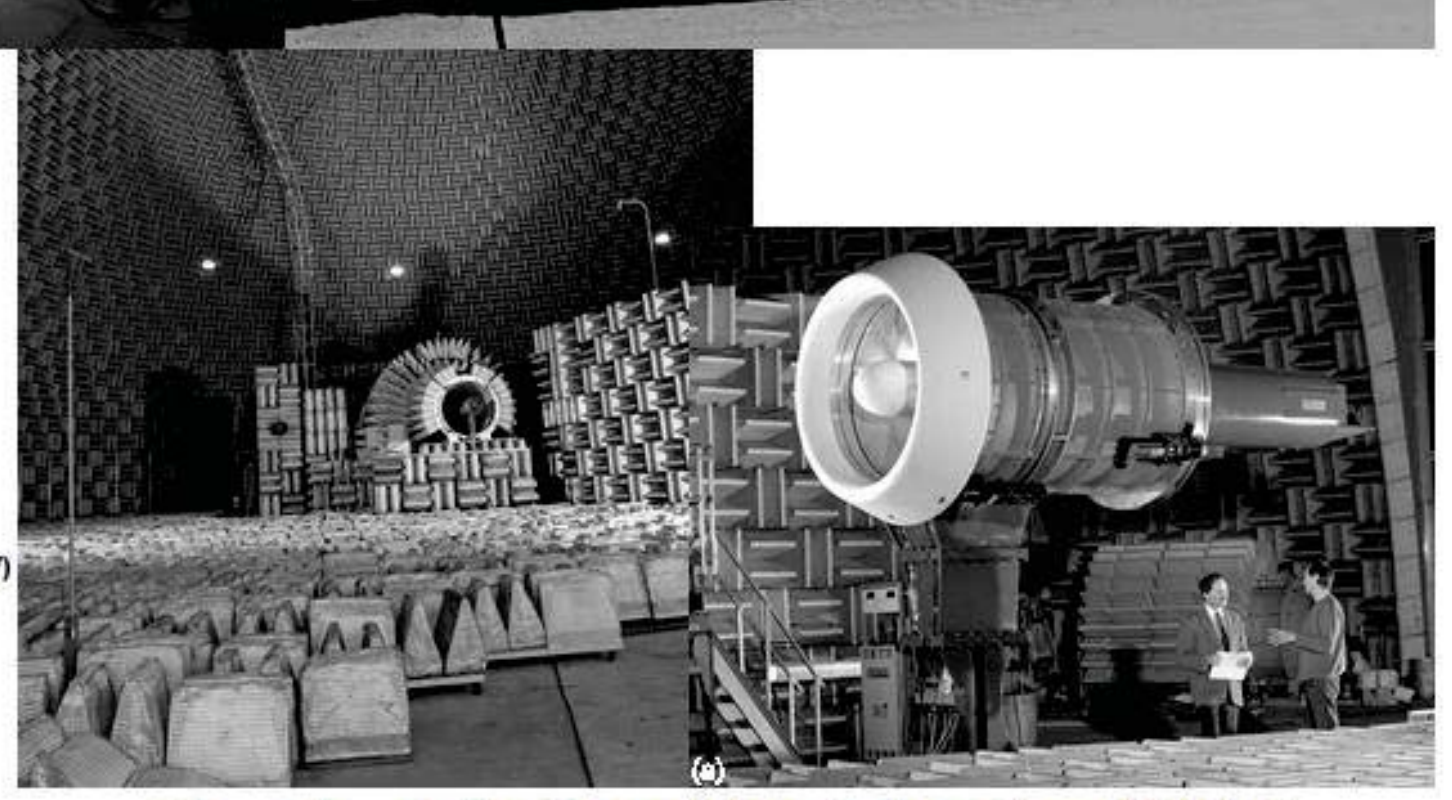

Aero-Acoustic Propulsion Laboratory (AAPL) 


\section{Noise Prediction Methods}

- ANOPP initiated at Langley in 1973, Lewis wrote engine noise modules still used today such as Heidmann fan and Stone jet.

- Rice equations: acoustic modes with similar cutoff ratios have similar directivity patterns. Liner design codes used by industry, optimum impedance correlate with cutoff ratio.

- Goldstein's SP-346 “Aeroacoustics” theoretical basis for many prediction methods throughout the world.

- JeNo: Jet noise prediction code by Khavaran shown to give accurate results for cold jets, still working hot jets.

- Envia RSI broadband fan noise prediction, interaction noise sources predicted within $4 \mathrm{~dB}$ of wind tunnel data over wide frequency range.

- Computational Aero Acoustics (CAA): GRC hosted 2 of 4 international workshops comparing predictions with benchmark problems. 


\section{Quiet Engine Program \& QCSEE (Late 1960s)}

- Quiet Engine Program (QEP) aimed to reduce engine noise by 15 to 20 PNdB below Boeing 707 and McDonnell-Douglas DC-8.

- First time Lewis involved in fan noise research.

- GE used experimental CF6 engine and delivered three fans with acoustically treated nacelles to test at Lewis.

- Quiet, Clean, Short-Haul, Experimental Engine (QCSEE) Program established to apply QEP technologies to short-haul aircraft, provide government with data for future rule making, and transfer data/technologies to industry.

Technologies from the QEP and QSCEE engines can be found in today's high bypass ratio engines.
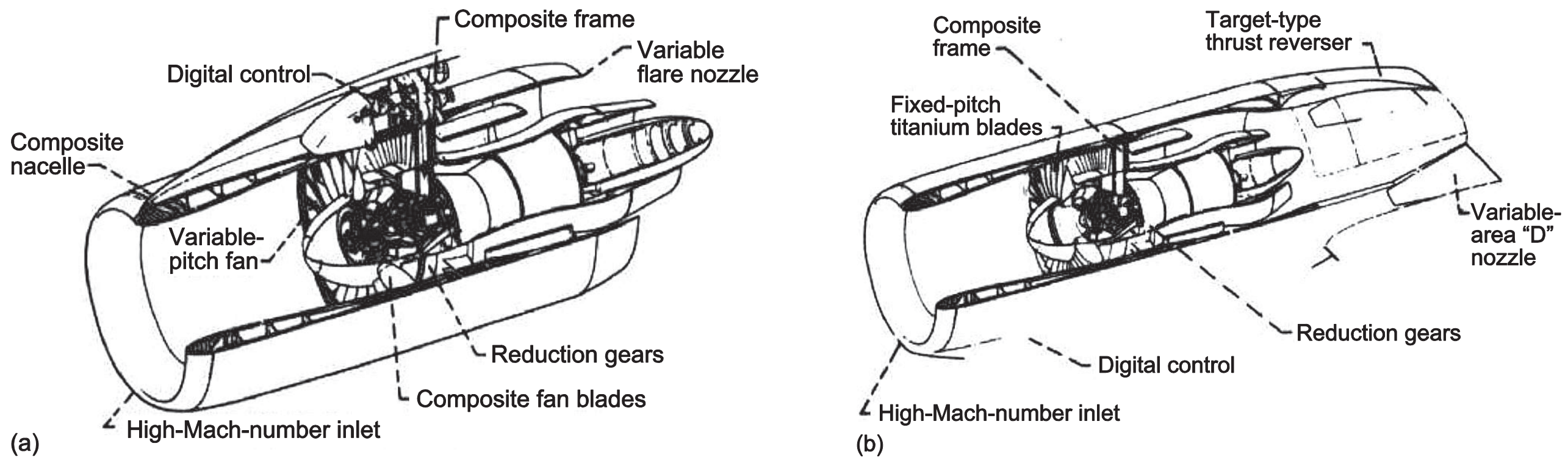


\section{Environment and Energy (1970s)}

- Refan program was initiated to develop retrofit engines for B727 and DC9 aircraft in 1972. Impacted 737-300 and MD-80 engine designs.

- QCGAT program started in 1976 to apply large engine noise reduction technologies to smaller engines, results met goals of 15 to $20 \mathrm{PNdB}$ below Chapter 3 noise regulations.

Key technologies included increasing fan diameter to increase the bypass ratio, single-stage fans replacing two-stage fans, increased spacing between blade rows, optimizing blade numbers, and incorporating acoustic treatment. Benefits of wing shielding for engine inlet noise also observed.
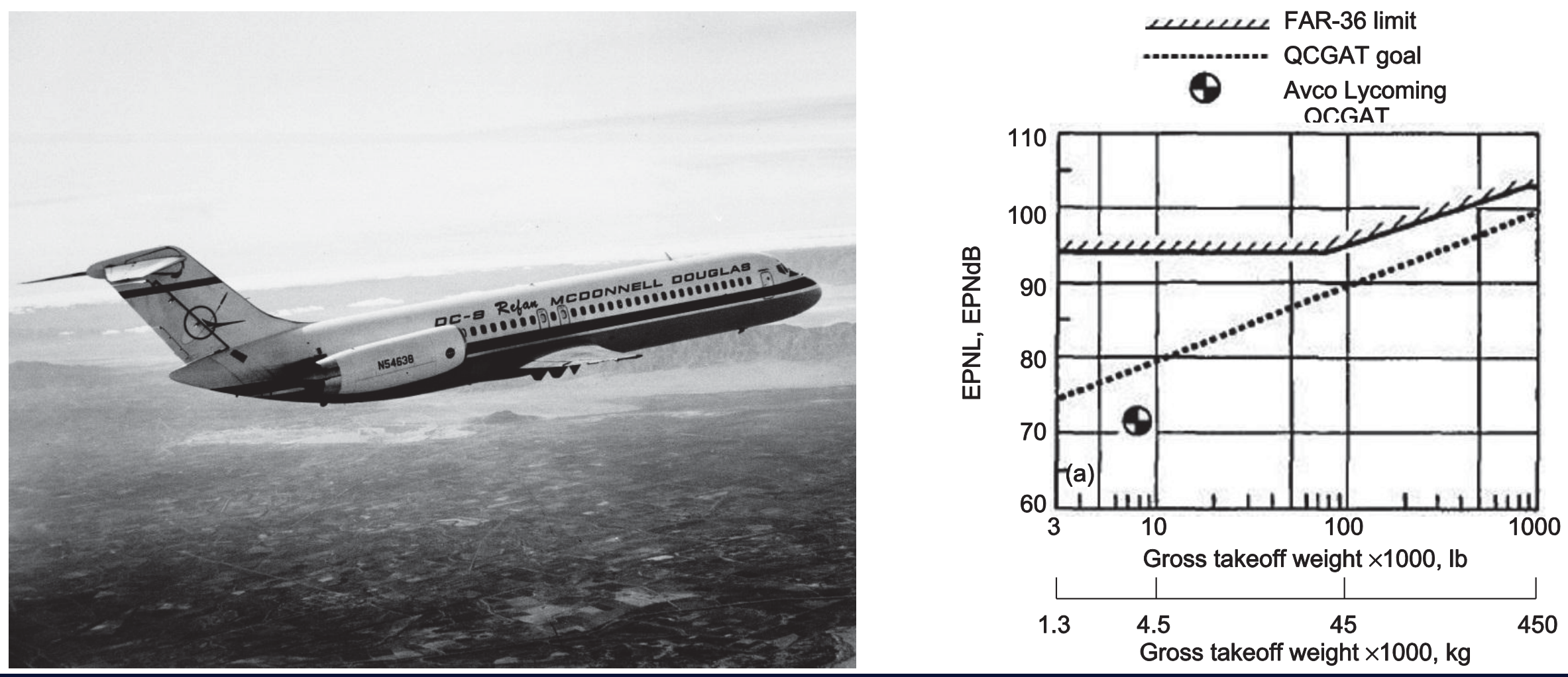


\section{Advanced Turboprop Program (1980s)}

- NASA's Aircraft Energy Efficiency Program consisted of the Energy Efficient Engine (EEE) and Advanced Turboprop (ATP) programs at Lewis.

- High-speed propellers capable of reducing fuel burn by 25 to $30 \%$ over equivalent technology turbofans.

- Community and cabin noise needed to be addressed.

GE's UDF (GE-36) flew on a modified B727 and MD-80. Noise levels just met Stage 3 regulations . Fuel efficiency benefits verified.
The Propfan Test Assessment (PTA) aircraft flew in 1987 using a singlerotation propeller called the SR-7. Good correlation with wind tunnel data.
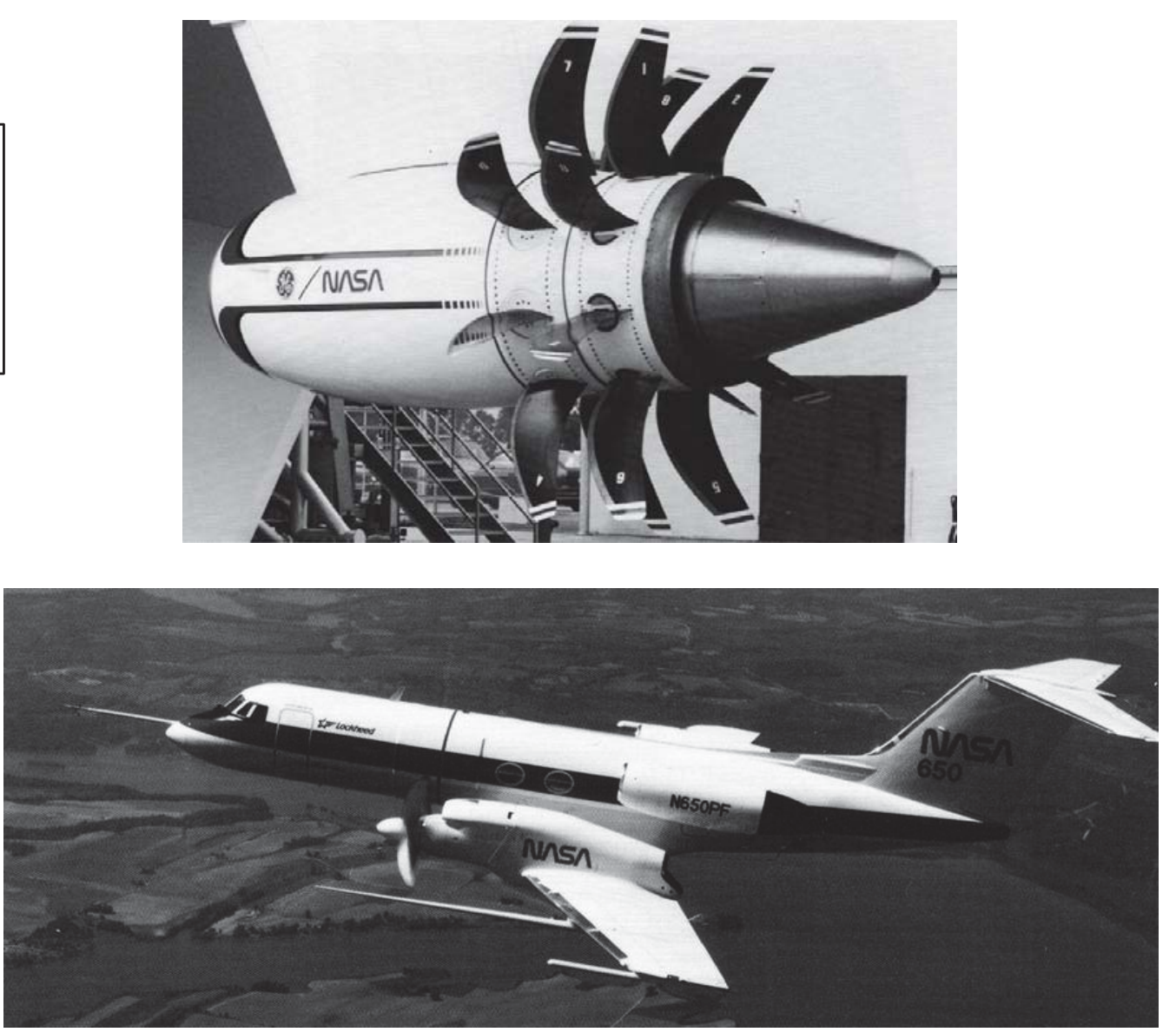


\section{High-Speed Research Program (1990s)}

- Lewis worked on jet noise reduction for the Supersonic Transport (SST) in the early 1970's.

- Research was resumed under HSR focusing on mixer-ejector nozzles.

- The noise reduction goal was $20 \mathrm{~dB}$ with acceptable thrust loss.

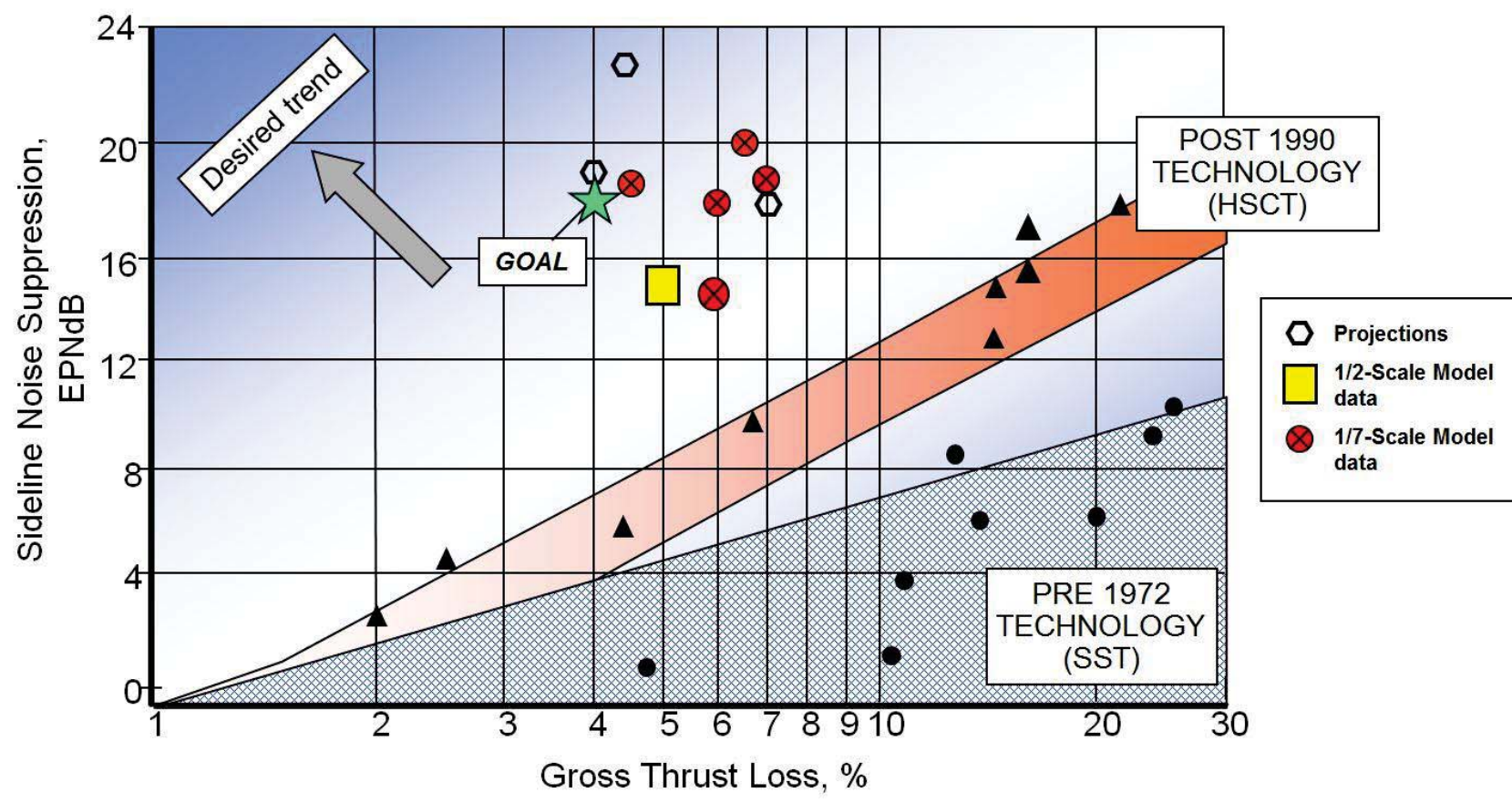

Significant progress was made with the help of CFD and lighter weight materials. Variable geometry required to optimize between takeoff and supersonic cruise.

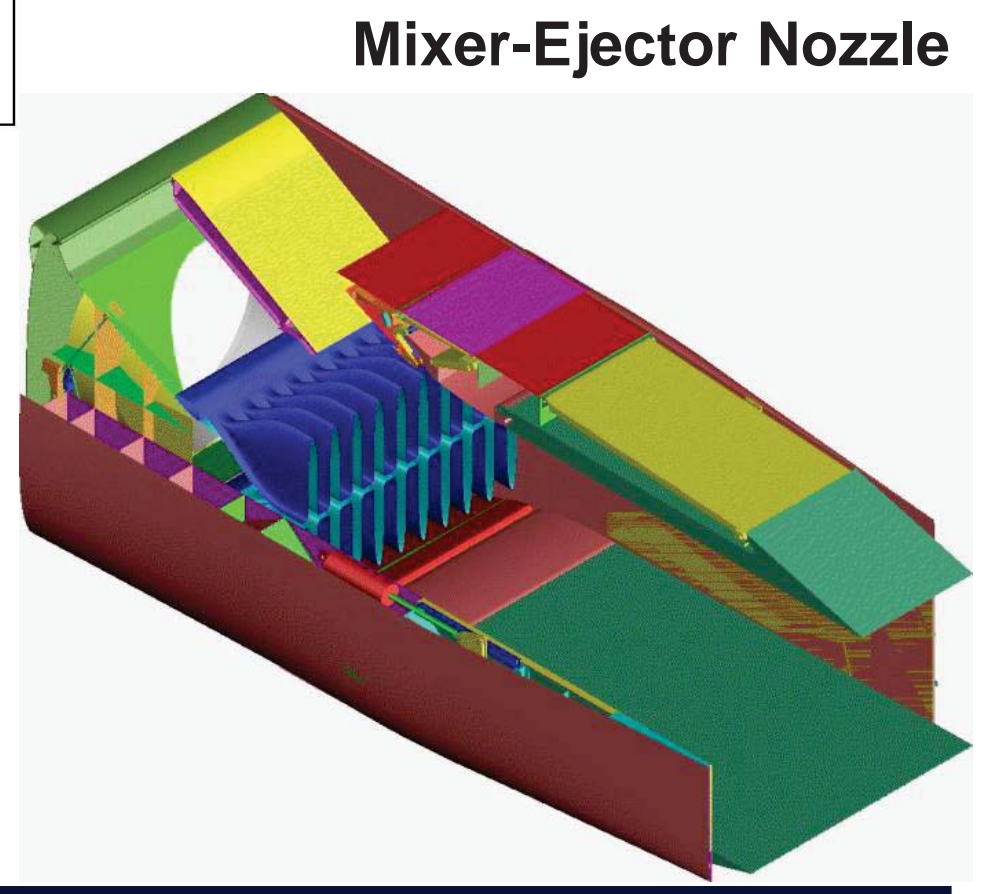


 \\ Advanced Subsonic Technology Program (1990\$)}

- Goal: 10 EPNdB noise reduction relative to 1992 technology.

- Selected noise reduction concepts validated with engine tests.

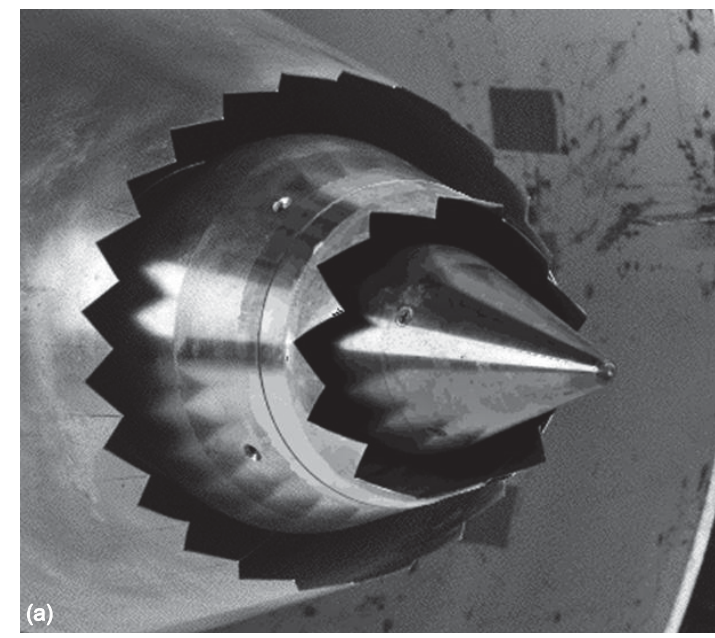

Chevron nozzles showed $3 \mathrm{~dB}$ jet noise reduction with minimal thrust loss.
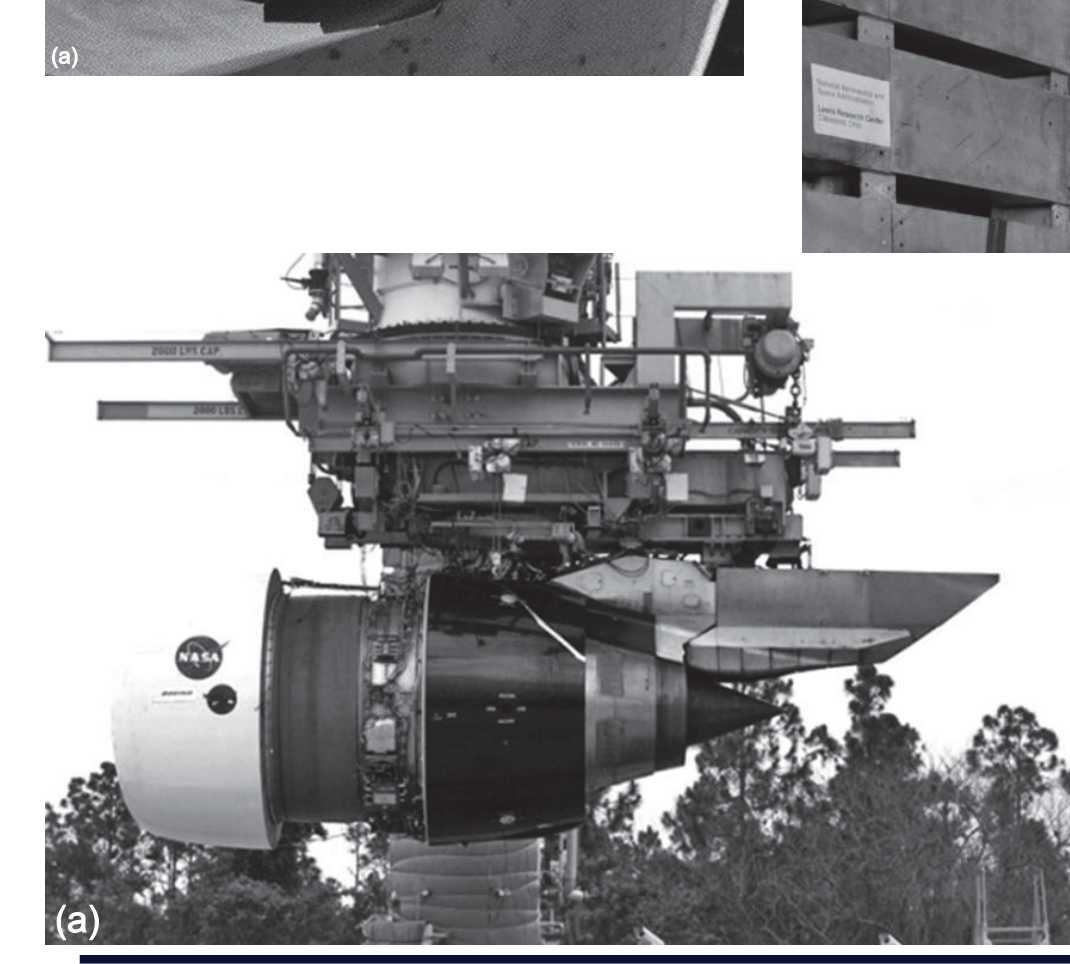

,

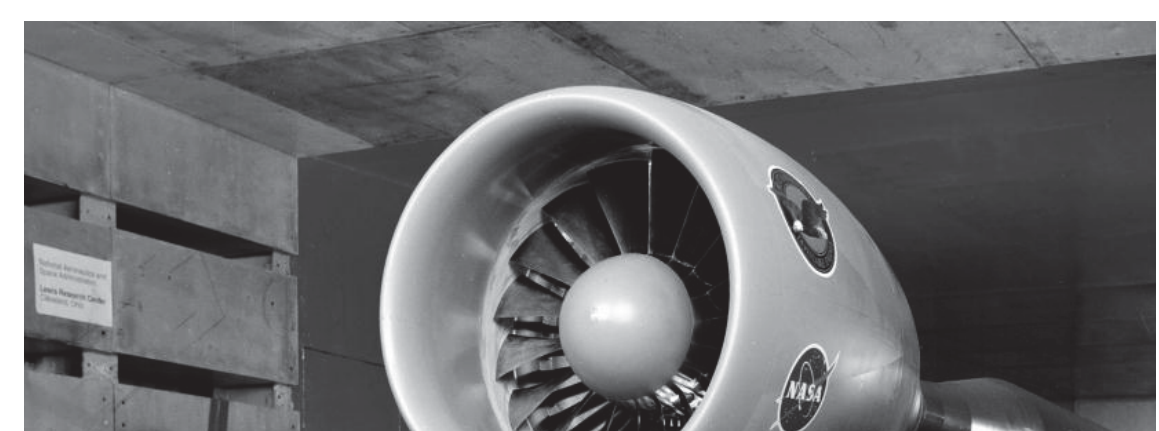

Low pressure ratio fans with swept stators significantly reduced fan noise.

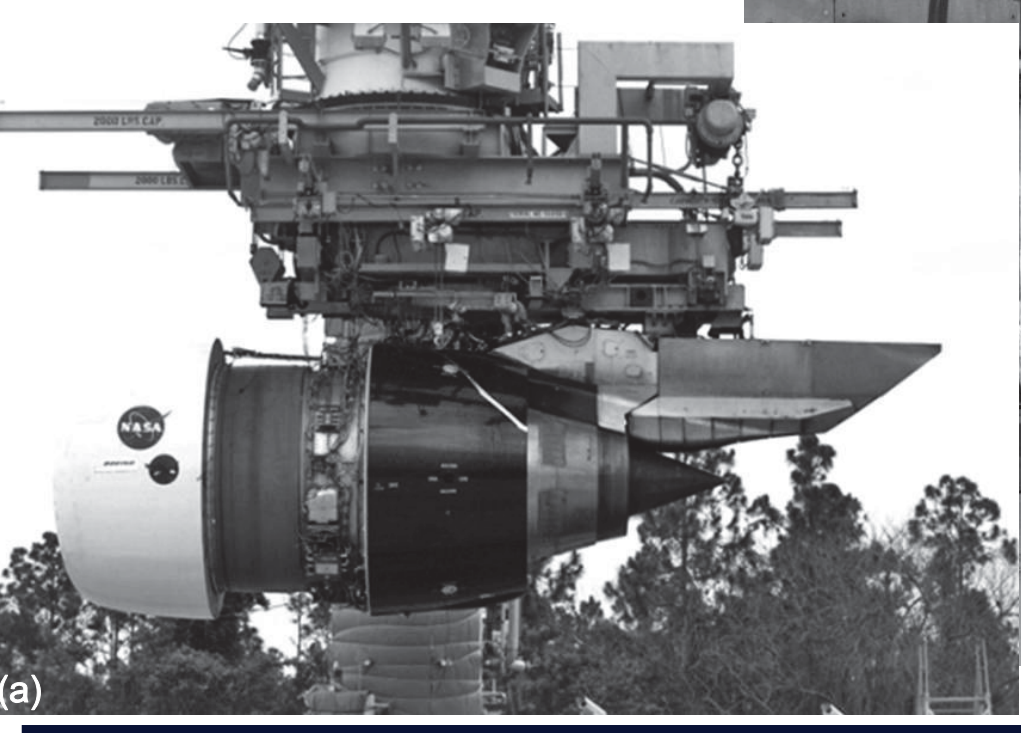

(49) $2+\infty$
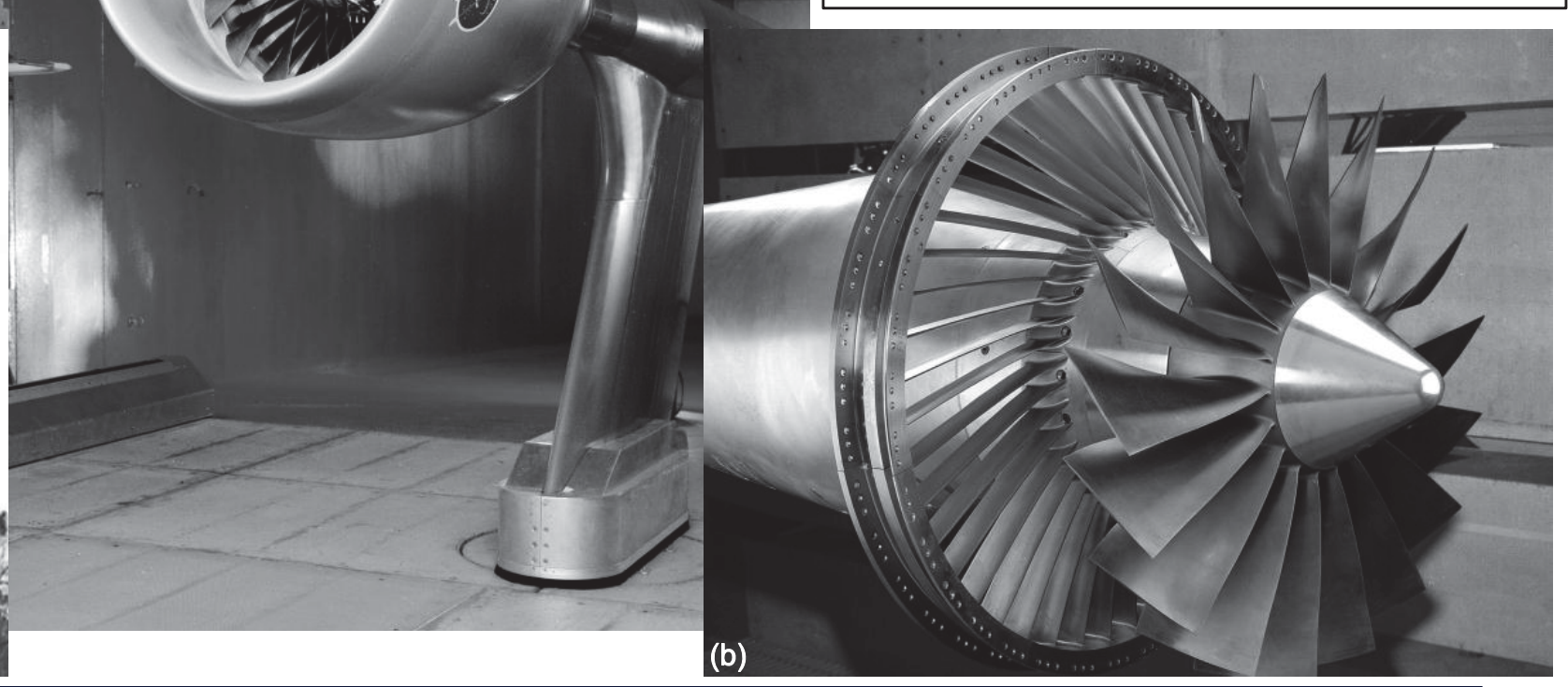


\section{Quiet Aircraft Technology Program (Early 2000s)}

- Focused on aft radiated fan noise and source diagnostic tests.
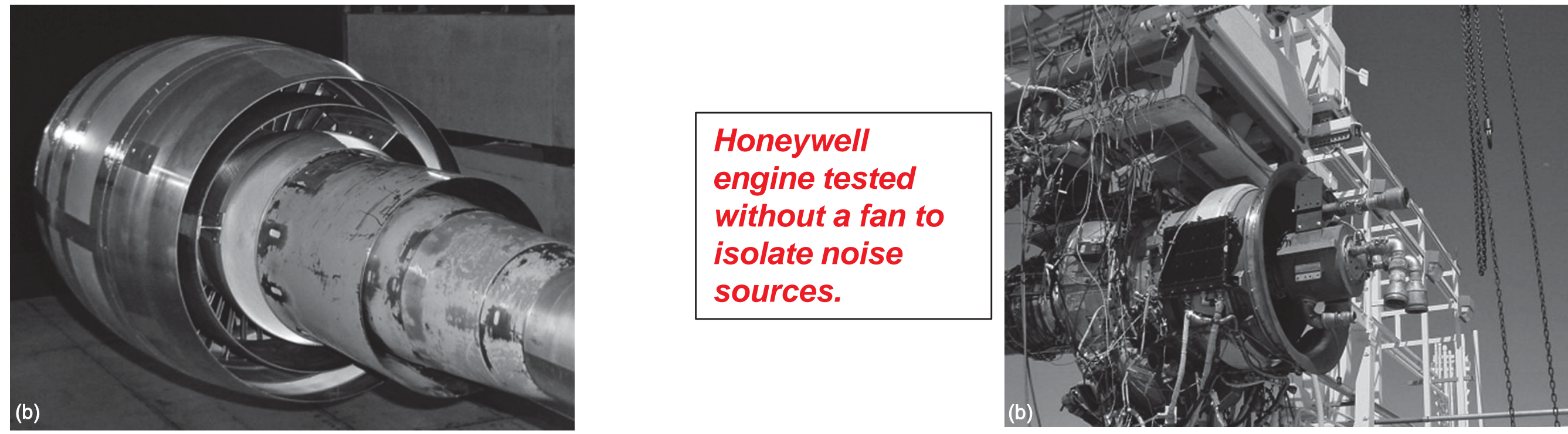

Fan duct treated splitter and trailing edge blowing tests showed mixed results.

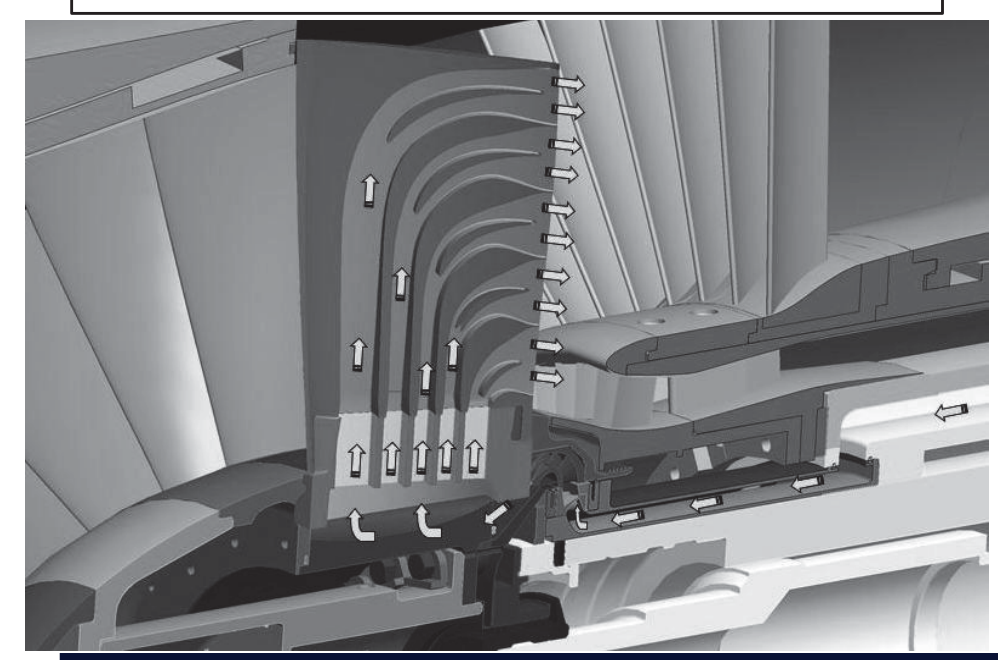

Honeywell engine tested without a fan to isolate noise sources.

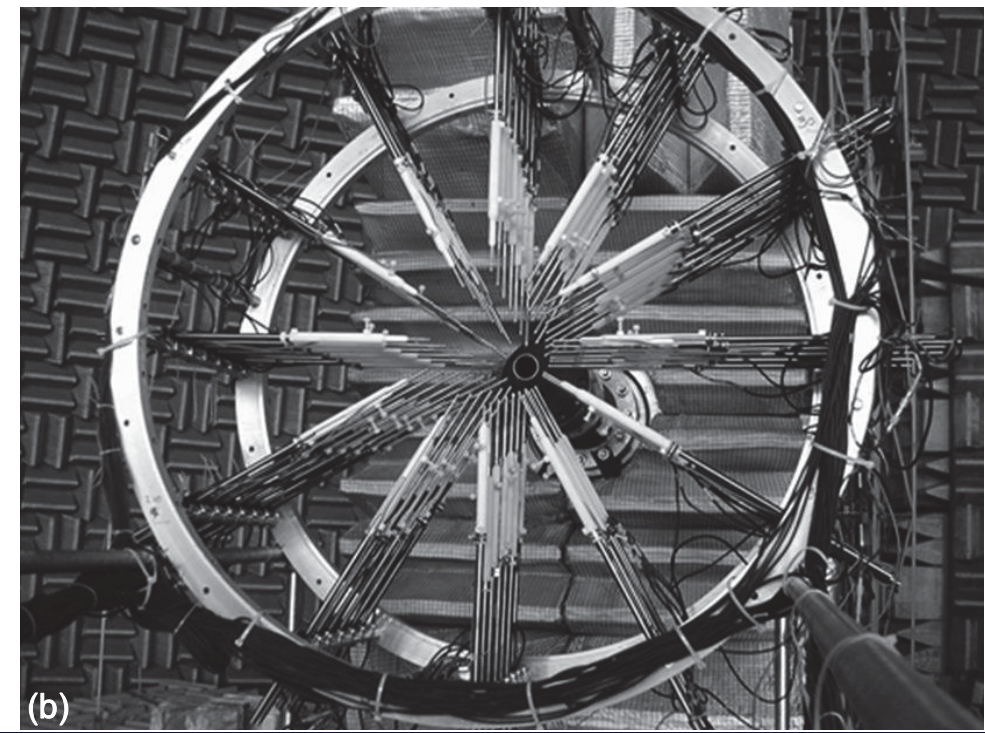

\section{Extensive} interrogation of jets with PIV and instability wave measurements. 


\section{Fundamental Aeronautics Program (Current)}

- Noise research split across subsonic, supersonic and rotorcraft projects.

- Established generational goals designated $\mathrm{N}+1, \mathrm{~N}+2$, and $\mathrm{N}+3$.

- Increased emphasis on shielding of engine noise with airframe.

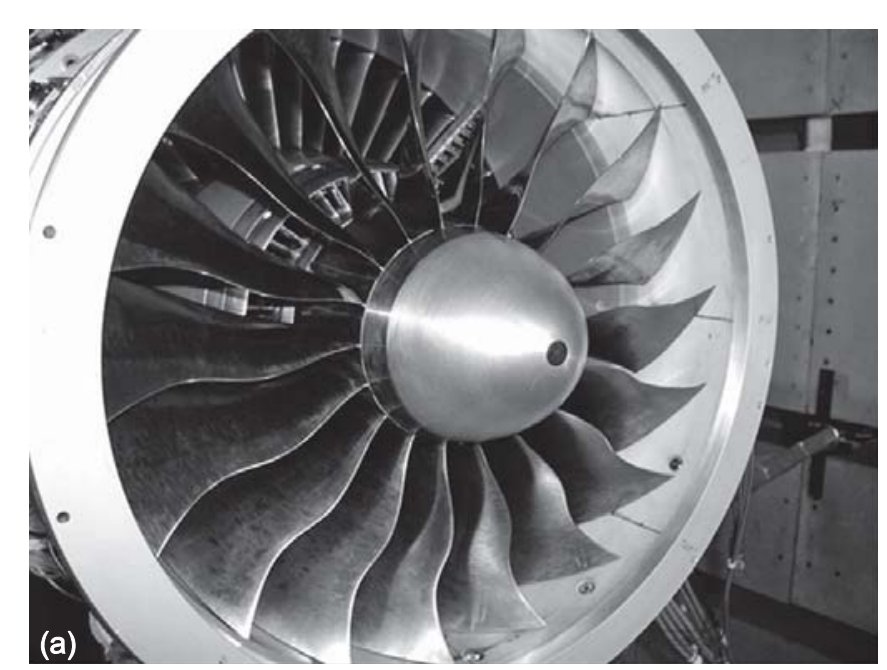

UHB

engines can meet $\mathrm{N}+1$

goals of -32

EPNdB cum

under

Chapter 4

regulations
Supersonic aircraft studying variable geometry engines and additional third stream for jet noise reduction and performance optimization. Can meet Chapter 4 regulations with margin.
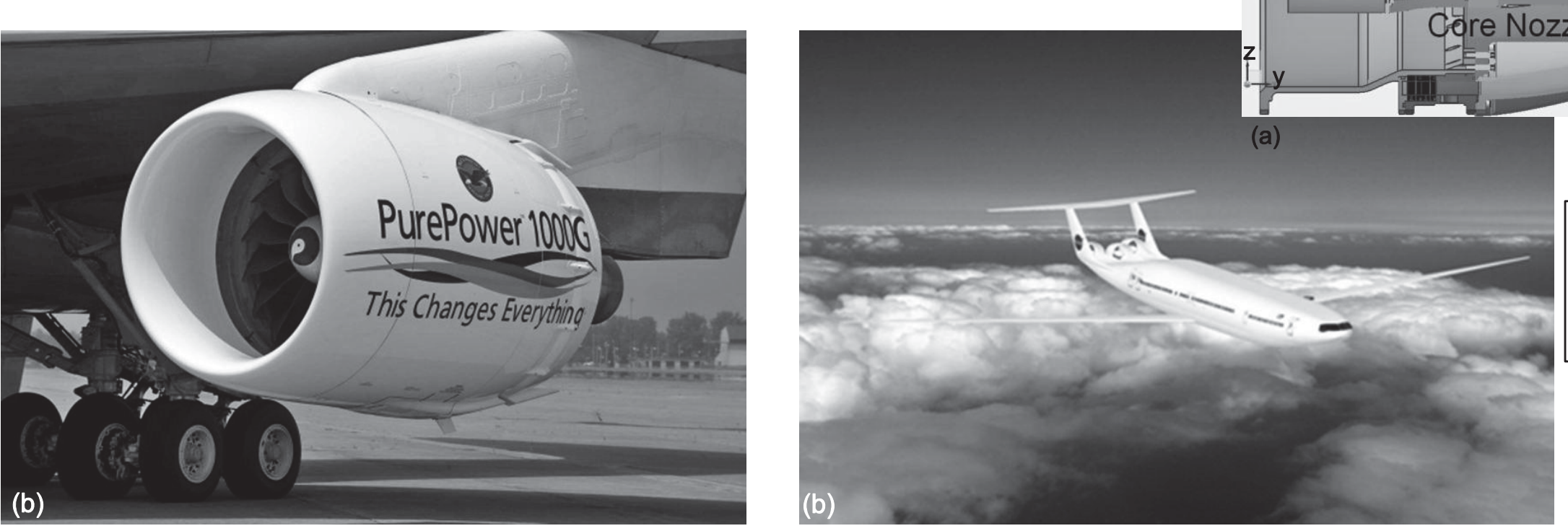

Shielding needed for additional noise reduction.

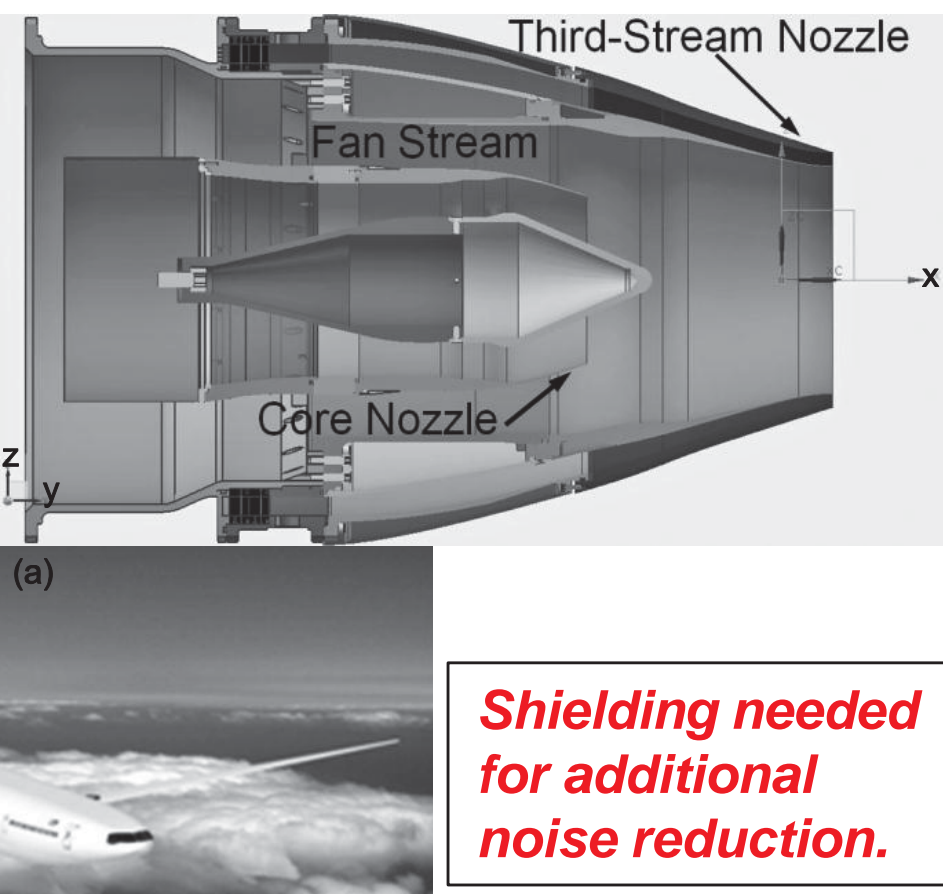




\section{Integrated Systems Research Program (Current)}

- Return of high-speed propellers, now called "Open Rotors"

- Tests and analyses compare UHB turbofans with Open Rotors.

NASA study provides independent assessment of noise and fuel efficiency. Results help ICAO for setting noise technology goals and future regulations.
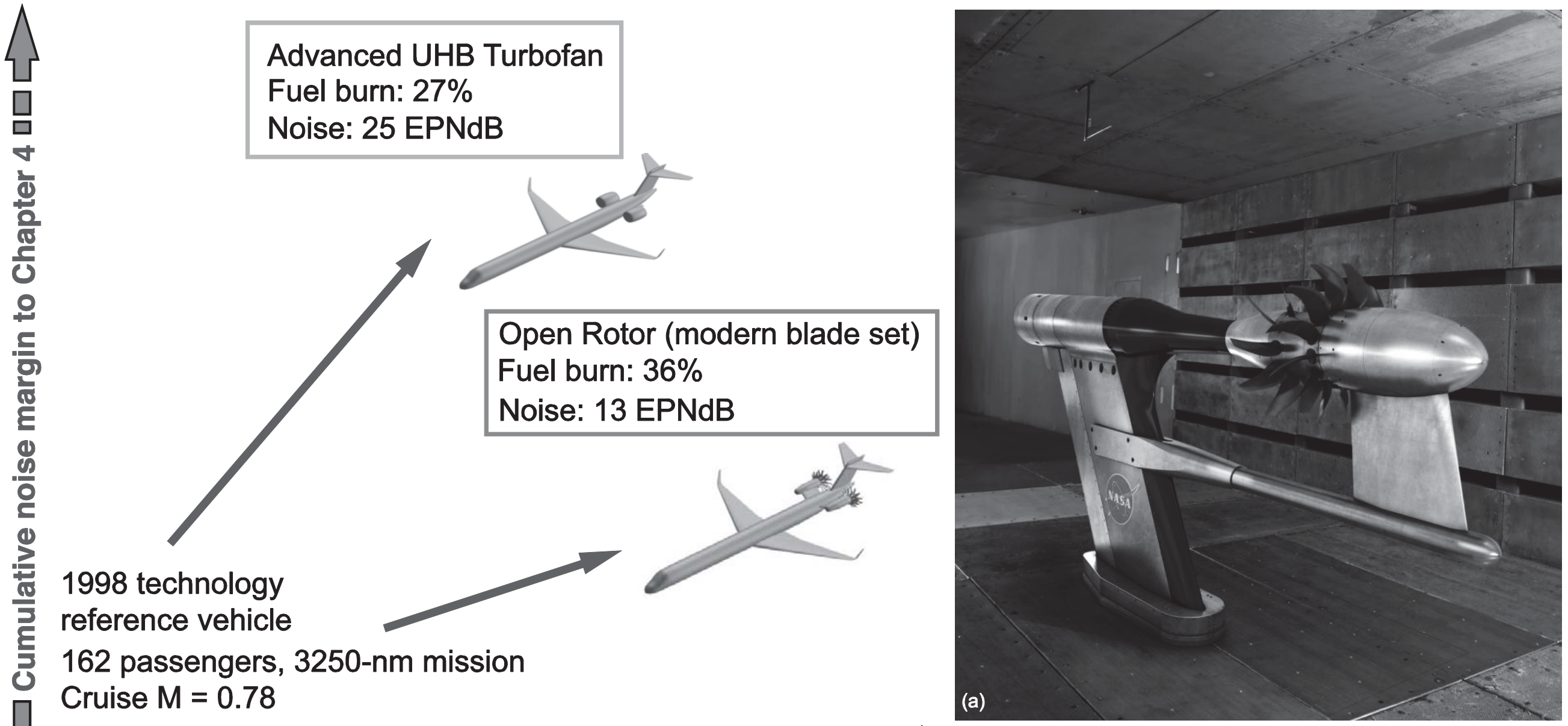
$\%$ Fuel burn benefit 마 


\section{Aircraft Noise Reduction Trends}

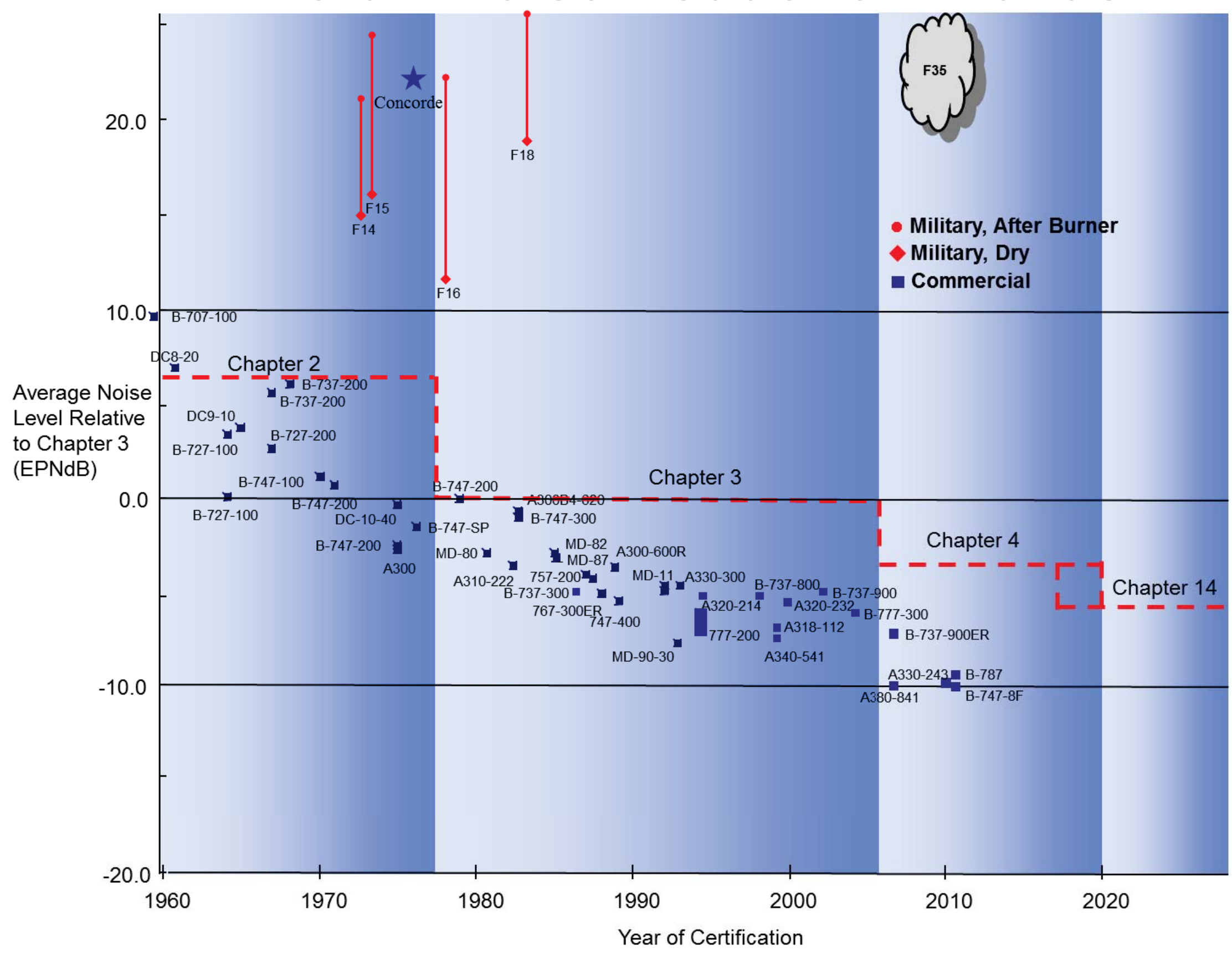




\section{Concluding Remarks}

- Tremendous progress has been made in aircraft noise reduction since the 1960s when regulations were first introduced. The average noise level has been reduced by about 20 EPNdB.

- NASA's ultimate goal is to contain the objectionable noise within the boundaries of an average airport. Studies show that this will require another 15 to 17 EPNdB noise reduction.

- NASA Glenn has made significant contributions toward achieving this goal.

Thanks to the hundreds of people at the NASA Glenn Research Center who have dedicated their professional careers to improving

the quality of life near the world's airports by developing technologies for reducing engine noise since the early 1950's. 